\title{
Genetic characterisation of multidrug-resistant Salmonella enterica serotypes isolated from poultry in Cairo, Egypt
}

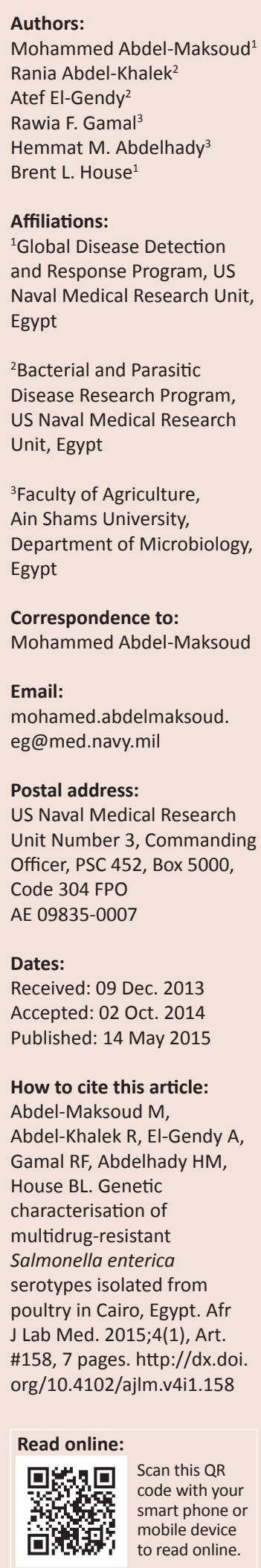

Authors:

Abdelhady

Affiliations:

Naval Medical Research Unit,

Egypt

${ }^{2}$ Bacterial and Parasitic

US Naval Medical Research

${ }^{3}$ Faculty of Agriculture

Ain Shams University,

Department of Microbiology,

Correspondence to:

Email:

mohamed.abdelmaksoud.

ed.navy.mil

Research

Officer, PSC 452, Box 5000 ,

Code 304 FPO

Dates:

Received: 09 Dec. 2013

Accepted: 02 Oct. 2014

How to cite this article:

Abdel-Maksoud M,

Abdel-Khalek R, El-Gendy A,

House BL. Genetic

characterisation of

multidrug-resistant poultry in Cairo, Egypt. Af

J Lab Med. 2015;4(1), Art.

\#158, 7 pages. http://dx.do

smart phone or

to read online.
Background: Food-borne diseases pose serious health problems, affecting public health and economic development worldwide.

Methods: Salmonella was isolated from samples of chicken parts, skin samples of whole chicken carcasses, raw egg yolks, eggshells and chicken faeces. Resulting isolates were characterised by serogrouping, serotyping, antimicrobial susceptibility testing and detection of extendedspectrum $\beta$-lactamase (ESBL) production. Antibiotic resistance genes and integrons were identified by polymerase chain reaction (PCR).

Results: The detection rates of Salmonella were $60 \%, 64 \%$ and $62 \%$ in chicken parts, skin, and faeces, respectively, whereas the egg yolks and eggshells were uniformly negative. Salmonella Kentucky and S. Enteritidis serotypes comprised $43.6 \%$ and $2.6 \%$ of the isolates, respectively, whilst S. Typhimurium was absent. Variable resistance rates were observed against 16 antibiotics; $97 \%$ were resistant to sulfamethoxazole, $96 \%$ to nalidixic acid and tetracycline and $76 \%$ to ampicillin. Multidrug resistance was detected in $82 \%(64 / 78)$ of the isolates and ESBL production was detected in $8 \%(6 / 78)$. The $\beta$-lactamase blaTEM-1 gene was detected in $57.6 \%$ and blaSHV-1 in $6.8 \%$ of the isolates, whilst the blaOXA gene was absent. The sul1 gene was detected in $97.3 \%$ and the sul2 gene in $5.3 \%$ of the isolates. Sixty-four of the 78 isolates (82\%) were positive for the integrase gene (int I) from class 1 integrons, whilst int II was absent.

Conclusion: This study reveals the presence of an alarming number of multidrug-resistant Salmonella isolates in the local poultry markets in Cairo. The high levels of drug resistance suggest an emerging problem that could impact negatively on efforts to prevent and treat poultry and poultry-transmitted human diseases in Egypt.

\section{Introduction}

Food-borne diseases caused by non-typhoid Salmonella present an important public health problem that impacts significantly on the economy in many parts of the world. The main source of infection is food of animal origin, such as poultry, eggs, milk, beef and pork. In addition, fruits and vegetables have been implicated as vehicles for Salmonella transmission. ${ }^{1}$

Antibiotics are used extensively to prevent or treat microbial infections in veterinary medicine. Microbial infections may be detected at various levels in animal products and disseminated into the environment when manure is applied to fields. ${ }^{2}$ In the last two decades, antimicrobial resistance has emerged quickly amongst Salmonella isolates, creating a serious health hazard worldwide. ${ }^{1}$

Although fluoroquinolones have recently been used as the drug of choice to treat gastrointestinal infections in humans, resistant strains have since emerged and have been associated with increased illness and death. ${ }^{3}$ Whereas fluoroquinolones are contraindicated because of toxicity, cephalosporins have also been used to treat salmonellosis, particularly in children. However, resistance to this class of drugs appeared in 1992, mainly because of the emergence of extendedspectrum $\beta$-lactamases (ESBLs). ${ }^{4}$

ESBLs comprise rapidly evolving groups of $\beta$-lactamases, capable of hydrolysing (and thus inactivating) third-generation cephalosporins and aztreonam, which are inhibited by the $\beta$-lactamase inhibitor, clavulanic acid. ${ }^{5}$ The ESBLs are encoded frequently by genes located on R-plasmids, which often carry additional genes encoding resistance to other drug classes (e.g. fluoroquinolones and aminoglycosides). ${ }^{6}$ ESBL-producing strains of bacteria are emerging 
worldwide, particularly amongst the Enterobacteriaceae ${ }^{7}$ where the exchange of multidrug-resistant (MDR) plasmids between members of the family is common. This MDR can lead to severe limitations in treatment options for infection with these microorganisms, which are responsible for nearly half of all human infections. ${ }^{8}$

The presence of integron gene sequences has been identified as a primary method by which bacteria can acquire existing antimicrobial resistance genes. Each integron sequence is unique in that it acts as a site-specific recombination system capable of capturing or excising novel genetic elements called 'gene cassettes'. These gene cassettes are promotorless genes with a recombination site known as a 59-base element or att C located at the $3^{\prime}$ end of the gene. The gene cassettes code for a wide range of antimicrobial resistant determinants. ${ }^{9}$ Only class 1 and 2 integrons have been detected in Salmonella, with class 1 being the most predominant. ${ }^{10}$

In Egypt, antibiotic resistance has been reported amongst human Salmonella isolates, including Salmonella enterica serovar Typhi (S. Typhi) and other diarrhoeagenic strains. ${ }^{11,12}$ However, with no national Salmonella surveillance centre to provide reliable statistical data, little is known about food-borne salmonellosis in Egypt. The present study was undertaken to determine the contamination rates of different Salmonella serotypes in chicken eggs, raw chicken meat and related environmental samples in poultry markets in Cairo, Egypt; and to characterise the identified isolates by serotype, antimicrobial susceptibility testing (AST) profiles and ESBL production. We also examined selected isolates to identify the presence of common antibiotic-resistance genes and integrons.

\section{Research methods and design Isolation and identification of Salmonella from poultry meat, egg and faecal samples}

A total of 165 samples were collected between December 2011 and May 2012 from 18 poultry markets (mostly street markets and retail shops that sell meat and live birds) distributed throughout 5 geographical locations in Cairo Governorate. The food samples were collected from 62 chicken meat parts ( 20 boneless breasts, 19 cloacae, 10 livers, 8 gizzards and 5 wings), 22 skin pieces from slaughtered birds, 30 raw egg yolks and shells from another 30 eggs. The faecal samples were collected from 21 separate chicken faeces specimens. The chicken parts and carcass samples were taken from different birds; all samples were cultured within 2 hours. The faecal samples were obtained from the same 18 poultry markets.

Salmonella strains were isolated and identified according to standard methods, ${ }^{13}$ and colonies that exhibited typical biochemical reactions were further confirmed as Salmonella using the API 20E identification kit (Biomerieux, Craponne, France).

\section{Serogrouping and serotyping of Salmonella isolates}

Biochemically identified Salmonella isolates were serogrouped initially by slide agglutination using commercially-available Salmonella $\mathrm{O}$ antiserum (Difco Laboratories, Detroit, MI, United States). Because of funding limitations, only serogroup B, C2 and D isolates were then serotyped for $S$. Typhimurium, S. Enteritidis and $S$. Kentucky according to the Kauffman White scheme, ${ }^{14}$ using Salmonella H antisera (Sifin, Germany; Statens, Denmark).

\section{Antibiotic susceptibility testing and detection of extended-spectrum $\beta$-lactamase production}

Antimicrobial susceptibilities to tetracyclines (tetracycline), sulphonamides (sulfamethoxazole trimethoprim/ sulphamethoxazole), quinolones (nalidixic acid), penicillins (ampicillin), penicillin/ $\beta$-lactamase inhibitor combinations (ticarcillin/clavulanate, ampicillin/sulbactam), phenicols (chloramphenicol), fluoroqinolones (ciprofloxacin), aminoglycosides (streptomycin, gentamicin, amikacin), monobactams (aztreonam), cephalosporins (cefotaxime, ceftriaxone, ceftazidime, cefepime) and carbapenems (imipenem) were determined using Kirby-Bauer disc diffusion according to Clinical and Laboratory Standards Institute $(\mathrm{CLSI})^{15}$ guidelines. In addition, minimum inhibitory concentration (MIC) was determined using E-test methods (AB Biodisk, Solana, Sweden), also according to CLSI guidelines. MDR Salmonella was defined as any isolate that showed resistance to at least three different classes of antibiotics. ${ }^{11}$

Screening for ESBL production in Salmonella isolates was done using the standard procedure of measuring the zones of inhibition surrounding cefotaxime and ceftazidime discs versus cefotaxime-clavulanic acid and ceftazidime-clavulanic acid discs, respectively. Any isolate with a $\geq 5 \mathrm{~mm}$ increase in zone diameter for either antibiotic tested in combination with clavulanic acid, versus without clavulanic acid, was considered to be an ESBL producer. ${ }^{15}$ The reference strains Escherichia coli ATCC 25922 and Staphylococcus aureus ATCC 25923 were used to verify the quality and accuracy of testing procedures.

\section{Detection of antimicrobial resistance genes}

Salmonella-isolate DNA was purified using the DNA-boiling method suggested by Sambrook, Fritsch and Maniatis. ${ }^{16 .}$ The following genes implicated in antimicrobial resistance were detected by PCR amplification: for $\beta$-lactam resistance blaTEM-1, blaSHV-1 and blaOXA-1; for sulphonamide resistance - sul1 and sul2. The primer sets and assay conditions used for amplification were as described previously. ${ }^{17,18}$

\section{Detection and characterisation of integrons}

The presence of class 1 and 2 integrase-coding genes (int I and int II) were detected by PCR with specific primers. ${ }^{17,19}$ Primers 5'-conserved segment (CS) and 3'-CS described by Levesque, ${ }^{20}$ targeting the inserted gene cassette regions of class 1 integrons, were used to determine these regions. 


\section{Statistical analysis}

For statistical analyses to detect significant differences between antibiotic resistance rates, $p$ values were determined by using Student's $t$-test in Microsoft ${ }^{\circledR}$ Office Excel 2010 (Microsoft Corp., Redmond, WA, United States).

\section{Results}

Salmonella isolates were recovered from 64 of the 165 samples collected, including $60 \%$ of chicken meat samples, $64 \%$ of chicken carcasses (skin) samples and $62 \%$ of chicken faeces samples. No Salmonella was isolated from raw egg yolk or eggshell samples.

Serogroups identified amongst the Salmonella isolates were B, C1, C2, and D. Fifty-one samples yielded isolates from one serogroup and 12 samples yielded isolates from 2 serogroups, whilst one sample from skin yielded 3 serogroups. Of the 78 Salmonella isolates obtained, group C2 was the predominant group found in chicken meat (Table 1). Serotypes identified included S. Kentucky (43.6\%) and S. Enteritidis (2.6\%) (Table 2). S. Typhimurium was not identified.

Overall, there was a high level of antibiotic resistance found amongst the Salmonella isolates (Table 3). Resistance was detected to 16 out of 18 antibiotics tested, whilst all Salmonella isolates were susceptible to imipenem and cefepime. Isolates demonstrated high levels of resistance to sulfamethoxazole (97\%), nalidixic acid and tetracycline (96\%), ampicillin (76\%), ticarcillin/clavulanate (67\%), chloramphenicol (56\%) and ciprofloxacin (46\%). Multidrug resistance was observed amongst $82 \%(64 / 78)$ of the isolates, with 59 isolates $(76 \%)$ resistant to more than 5 antibiotics. ESBL production was detected in $8 \%(6 / 78)$, with all 6 being highly resistant to

TABLE 1: Distribution of Salmonella serogroups isolated from 144 poultry samples and 21 faecal samples collected between December 2011 and May 2012

\begin{tabular}{lccc}
\hline $\begin{array}{l}\text { Salmonella } \\
\text { serogroups }\end{array}$ & \multicolumn{2}{c}{ No. of isolates in each serogroup (\% of sample type) } \\
\cline { 2 - 4 } & $\begin{array}{c}\text { Chicken meat and } \\
\text { skin samples } \dagger\end{array}$ & Faecal samples: & Total \\
\hline Group B & $12(18.5)$ & $3(23)$ & $15(19.2)$ \\
Group C1 & $21(32.3)$ & $2(15)$ & $23(29.5)$ \\
Group C2 & $30(46.2)$ & $8(62)$ & $38(48.7)$ \\
Group D & $2(3)$ & - & $\mathbf{2}(2.6)$ \\
\hline Total & 65 & 13 & 78 \\
\hline
\end{tabular}

A total of 144 samples were collected from 62 chicken meat parts $(20$ boneless breasts, (2) egg yolks and shells from another 30 eggs.

$¥$, A total of 21 samples were collected from chicken faeces.

TABLE 2: Distribution of serotypes for the 78 Salmonella isolates recovered from poultry and faecal samples collected between December 2011 and May 2012.

\begin{tabular}{lccc}
\hline $\begin{array}{l}\text { Salmonella } \\
\text { serotypes }\end{array}$ & \multicolumn{3}{c}{ No. of isolates in each serotype (\% of sample type) } \\
\cline { 2 - 4 } & $\begin{array}{l}\text { Chicken meat and } \\
\text { skin samples } \dagger\end{array}$ & Faecal samples: & Total \\
\hline S. Kentucky & $27(41.5)$ & $7(54)$ & $\mathbf{3 4}(\mathbf{4 3 . 6 )}$ \\
S. Enteritidis & $2(3.1)$ & - & $\mathbf{2}(2.6)$ \\
S. Typhimurium & - & - & - \\
Other serotypes $\S$ & $36(55.4)$ & $6(46)$ & $\mathbf{4 2}(53.8)$ \\
\hline
\end{tabular}

A total of 144 samples were collected from 62 chicken meat parts ( 20 boneless breasts, 19 cloacae, 10 livers, 8 gizzards and 5 wings), 22 skin pieces from slaughtered birds, 30 raw egg yolks and shells from another 30 eggs.

$\$$, A total of 21 samples were collected from chicken faeces.

$\S$, Further serotyping was not performed for these isolates because of funding limitations. multiple antibiotics when compared to non-ESBL producing strains. When compared with other Salmonella serotypes, the $S$. Kentucky isolates showed higher resistance rates to the majority of antibiotics tested, reaching statistical significance against ciprofloxacin and ticarcillin/clavulanate $(p<0.01)$. Sixteen (46\%) S. Kentucky strains were resistant to at least 8 antibiotics.

Amongst the 75 strains resistant to nalidixic acid, 36 were resistant to the related ciprofloxacin (MIC range of 4-12 $\mu \mathrm{g} / \mathrm{mL}$ ). Imipenem showed the lowest MIC values, followed by cefepime and amikacin, all of which were found to be effective against Salmonella strains isolated from poultry in Cairo. On the other hand, the highest MIC values were obtained against streptomycin, followed by nalidixic acid and ampicillin (Table 3 ).

Table 4 lists the resistance genes detected in the Salmonella isolates. The most frequent $\beta$-lactam gene identified amongst ampicillin resistant isolates was blaTEM-1, detected in 57.6\% of the isolates, followed by blaSHV-1 which was identified in $6.8 \%$. The blaOXA-1 gene was not detected in any isolate in this study. Regarding sulphonamide resistance genes, the presence of the sul1 gene was detected in $97.3 \%$ of the isolates and the sul 2 gene in $5.3 \%$. Four isolates possessed both the sul1 and sul2 genes (Table 4).

Sixty-four of the 78 isolates $(82 \%)$ were positive for the int I gene, whilst int II was absent. The 5'- and 3'-CS regions were identified in $46.8 \%$ of the int I positive isolates. Eight types of class 1 integrons were detected for the Salmonella spp. isolates, including the $1950 \mathrm{bp}, 1550 \mathrm{bp}, 1200 \mathrm{bp}, 1100 \mathrm{bp}$, $1000 \mathrm{bp}, 700 \mathrm{bp}$, a combination of $950 \mathrm{bp}$ and $1200 \mathrm{bp}$ and a combination of $1100 \mathrm{bp}$ and $1550 \mathrm{bp}$ integrons. Five $S$. Kentucky isolates resistant to ciprofloxacin carried the 1950 bp class 1 integron (Table 5).

\section{Discussion}

The objectives of this study were to determine the frequency of Salmonella contamination of chicken eggs, meat and faeces in poultry markets in Cairo, Egypt and to identify prevalent serotypes and antibiotic susceptibility profiles, including ESBL production. The results from this study revealed levels of Salmonella-contamination in fresh chicken meat of $60 \%-64 \%$, which are higher than those previously reported in Assiut, Egypt from frozen chicken legs and fillet samples $(36 \%-52 \%) ;{ }^{21}$ in Senegal from chicken carcasses (32\%); ${ }^{22}$ and in Ethiopia from raw chicken meat and giblets $(18 \%) .{ }^{23}$ In contrast to a study conducted by Del Cerro et al. ${ }^{24}$ which reported that faeces from chickens were positive for Salmonella by culture in $39 \%$ of the samples tested, our study demonstrated a $62 \%$ positivity rate for Salmonella isolation from faecal specimens. The high contamination rates seen in this study may, at least in part, be explained by the lack of hygienic slaughtering processes that occur commonly at small shops, away from the modern abattoirs available for 
TABLE 3: Percent antibiotic resistance and MIC range of S. Kentucky, other Salmonella serotypes and ESBL-producing Salmonella isolates from poultry meat and faecal samples.

\begin{tabular}{|c|c|c|c|c|c|}
\hline \multirow[t]{2}{*}{ Class and antibiotics ( $\mu \mathrm{g} / \mathrm{disc})$} & \multirow{2}{*}{$\begin{array}{c}E \text {-test } \\
\text { MIC Range } \mu \mathrm{g} / \mathrm{mL}\end{array}$} & \multicolumn{4}{|c|}{ Disk diffusion: No. of samples demonstrating resistance (percentage of isolates resistant) } \\
\hline & & $\begin{array}{c}\text { Salmonella Kentucky } \\
(n=32) \dagger\end{array}$ & $\begin{array}{l}\text { Other Salmonella } \\
\text { serotypes }(n=40)\end{array}$ & $\begin{array}{l}\text { Salmonella ESBL- } \\
\text { producers }(n=6)\end{array}$ & Total $(n=78)$ \\
\hline \multicolumn{6}{|l|}{ Sulphonamides } \\
\hline Trimethoprim/Sulphamethoxazole $(1.25 \mu \mathrm{g} / 23.75 \mu \mathrm{g})$ & $0.094->32$ & $23(72)$ & $14(35)$ & $3(50)$ & $40(51)$ \\
\hline \multicolumn{6}{|l|}{ Tetracyclines } \\
\hline Tetracycline $(30 \mu \mathrm{g})$ & $2->256$ & $31(97)$ & $38(95)$ & $6(100)$ & 75(96) \\
\hline Naldixic acid $(30 \mu \mathrm{g})$ & $4->256$ & $30(94)$ & $39(98)$ & $6(100)$ & 75 (96) \\
\hline \multicolumn{6}{|l|}{ Penicillins } \\
\hline Ampicillin $(10 \mu g)$ & $24->256$ & $31(97)$ & $22(55)$ & $6(100)$ & $59(76)$ \\
\hline \multicolumn{6}{|l|}{$\beta$-lactamases } \\
\hline Ticarcillin/clavulanate $(75 / 10 \mu \mathrm{g})$ & NA & $30(94) \ddagger$ & $17(43) \ddagger$ & $5(83)$ & $52(67)$ \\
\hline Ampicillin/sulbactam ( $10 / 10 \mu \mathrm{g}$ ) & $3-256$ & $11(34)$ & $12(30)$ & $2(33)$ & $25(32)$ \\
\hline \multicolumn{6}{|l|}{ Phenicols } \\
\hline \multicolumn{6}{|l|}{ Fluoroquinolones } \\
\hline Ciprofloxacin (5 $\mu \mathrm{g})$ & $0.19-12$ & $31(97) \ddagger$ & $1(3) \div$ & $4(66)$ & $36(46)$ \\
\hline \multicolumn{6}{|l|}{ Aminoglycosides } \\
\hline Streptomycin $(10 \mu \mathrm{g})$ & $0.38-512$ & $1(3)$ & $21(53)$ & $6(100)$ & $28(36)$ \\
\hline Gentamicin $(10 \mu \mathrm{g})$ & $0.38-24$ & $9(28)$ & $13(33)$ & $3(50)$ & $24(31)$ \\
\hline Amikacin $(30 \mu \mathrm{g})$ & $1-2$ & $1(3)$ & 0 & 0 & $1(1)$ \\
\hline \multicolumn{6}{|l|}{ Monobactam } \\
\hline Aztreonam $(30 \mu \mathrm{g})$ & NA & $1(3)$ & 0 & $6(100)$ & 7 (9) \\
\hline \multicolumn{6}{|l|}{ Cephems } \\
\hline Cefotaxime $(30 \mu \mathrm{g})$ & $24->256$ & $1(3)$ & $1(3)$ & $6(100)$ & $8(10)$ \\
\hline Ceftriaxone $(30 \mu \mathrm{g})$ & $0.125->32$ & $1(3)$ & 0 & $4(66)$ & $5(6)$ \\
\hline Ceftazidime $(30 \mu \mathrm{g})$ & $0.38->256$ & $1(3)$ & 0 & $4(66)$ & $5(6)$ \\
\hline Cefepime (30 $\mu \mathrm{g})$ & $0.19-3$ & 0 & 0 & 0 & 0 \\
\hline \multicolumn{6}{|l|}{ Carbapenems } \\
\hline
\end{tabular}

TABLE 4: Antimicrobial resistance genes and the resistance phenotype of $S$. enterica strains isolated from poultry meat and faecal samples ( $n=78$ ).

\begin{tabular}{|c|c|c|c|c|c|c|}
\hline \multirow{3}{*}{$\begin{array}{l}\text { Class and } \\
\text { antimicrobial }\end{array}$} & \multirow{3}{*}{$\begin{array}{l}\text { No. of resistant } \\
\text { isolates (\%) }\end{array}$} & \multirow[t]{3}{*}{ Resistance gene } & \multicolumn{4}{|c|}{ Isolates containing the selected resistance gene } \\
\hline & & & \multirow[t]{2}{*}{ No. $(\%)$} & \multirow[t]{2}{*}{ Serovar distribution (no. of isolates) } & \multicolumn{2}{|c|}{ Origin and no. of isolates } \\
\hline & & & & & Poultry meat & Faecal samples \\
\hline \multirow{4}{*}{$\begin{array}{l}\text { B-Lactams } \\
\text { Ampicillin }\end{array}$} & $59(75.6)$ & blaTEM-1 & $34(57.6)$ & S. Kentucky (22), other serotypes (10) & 30 & 4 \\
\hline & & blaOXA-1 & 0 & - & - & - \\
\hline & & blaSHV-1 & $4(6.8)$ & Other serotypes (4) & 4 & - \\
\hline & & Others & $21(35.6)$ & S. Kentucky (9), other serotypes (12) & 16 & 5 \\
\hline & & sul2 & $4(5.3)$ & S. Kentucky (1), other serotypes (3) & 4 & - \\
\hline & & Others & $2(2.6)$ & Other serotypes (2) & 2 & - \\
\hline
\end{tabular}

mass slaughtering of poultry. At these shops, slaughtering is manual, rudimentary and may take place either indoors or outdoors. Usually, one person provides all the labour, including live bird care, cleaning, slaughtering, defeathering and evisceration, increasing the likelihood of cross-contamination amongst birds.

In this study, serogroups B, C1 and C2 accounted for $97 \%$ of the isolates from chicken meat. A similar study performed in the Pacific Northwest, in the United States ${ }^{25}$ also found that serogroups B and C comprised the majority (95\%) of all Salmonella isolated from poultry and the poultry environment. A study in Saudi Arabia ${ }^{26}$ reported that $64 \%$ of the isolates from poultry and the poultry environment were from groups B and C. In the current study, there were only two isolates assigned to serogroup D, subsequently serotyped as $S$. Enteritidis.

In humans, S. Enteritidis and S. Typhimurium have been reported to be the two most prevalent Salmonella serotypes in many regions of the world. ${ }^{26}$ In addition, a study in Turkey demonstrated that $S$. Enteritidis was the most prevalent Salmonella serotype isolated from chicken meat. ${ }^{27}$ However, a study in Senegal identified only $6 S$. Enteritidis serotypes out of 90 Salmonella strains isolated..$^{28}$ Another study in Sudan identified 2 chicken and 2 human origin $S$. Kentucky strains resistant to both ciprofloxacin and norfloxacin out of 64 Salmonella isolates studied. ${ }^{29}$ 
TABLE 5: Characteristics of class 1 integron-carrying multidrug-resistant $S$. enterica strains isolated from poultry meat and faecal samples $(n=64)$.

\begin{tabular}{|c|c|c|c|c|c|c|c|c|}
\hline \multirow{2}{*}{$\begin{array}{l}\text { Amplicon size in } \\
\text { class } 1 \text { integron- } \\
\text { PCR (bp) }\end{array}$} & \multirow[t]{2}{*}{ No. $(\%)$} & \multirow[t]{2}{*}{ Resistance genes } & \multirow[t]{2}{*}{ Antibiotic resistance profile $\uparrow$} & \multirow[t]{2}{*}{ ESBL } & \multirow{2}{*}{$\begin{array}{l}\text { Serogroup } \\
\text { (no. of isolates) }\end{array}$} & \multirow[t]{2}{*}{ Serotype $\$$} & \multicolumn{2}{|c|}{ Origin and no. of isolates } \\
\hline & & & & & & & Poultry meat & Faecal samples \\
\hline 700 & $2(3.1)$ & sul1, blaTEM-1 & SUL, NA, TE, TIM, C, SXT, SAM & - & B (1), C2 (1) & N/A & 2 & - \\
\hline 700 & $2(3.1)$ & $\begin{array}{l}\text { sul1, blaTEM-1, } \\
\text { blaSHV-1 }\end{array}$ & $\begin{array}{c}\text { SUL, NA, TE, AM, S, TIM, SXT, } \\
\text { CTX, ATM, CAZ }\end{array}$ & + & $B(2)$ & N/A & 2 & - \\
\hline $950-1200$ & $1(1.6)$ & sul1 & SUL, NA, TE, S, TIM, SXT & - & $\mathrm{C} 1(1)$ & N/A & 1 & - \\
\hline 1000 & $10(15.6)$ & sul1, sul2, blaTEM-1 & SUL, NA, TE AM & - & C1 (9), C2 (1) & N/A & 8 & 2 \\
\hline 1100 & $2(3.1)$ & sul1 & SUL, NA, TE S, TIM, SXT & - & $B(2)$ & N/A & 1 & 1 \\
\hline $1100-1550$ & $4(6.3)$ & sul1, blaTEM-1 & SUL, NA, TE AM, S, GM, SAM & - & $B(4)$ & N/A & 4 & - \\
\hline 1200 & $2(3.1)$ & sul1, sul2, blaTEM-1 & SUL, NA, TE AM & - & $\mathrm{C} 1(2)$ & N/A & 2 & - \\
\hline 1550 & $2(3.1)$ & sul1, blaTEM-1 & SUL, NA, TE AM S, GM, CIP & - & $\mathrm{C} 2(2)$ & S. Kentucky & 2 & - \\
\hline 1950 & $5(7.8)$ & sul1, blaTEM-1 & SUL, NA, TE, CIP & - & C2 (5) & S. Kentucky & 4 & 1 \\
\hline No amplicon & $30(46.9)$ & $\begin{array}{l}\text { sul1, sul2, blaTEM-1, } \\
\text { blaSHV-1 }\end{array}$ & SUL, NA, TE & - & B (5), C1 (6), C2 (19) & $\begin{array}{l}\text { S. Kentucky (18), } \\
\text { N/A (12) }\end{array}$ & 26 & 4 \\
\hline No amplicon & $4(6.3)$ & $\begin{array}{l}\text { sul1, sul2, blaTEM-1, } \\
\text { blaSHV-1 }\end{array}$ & SUL, NA, TE AM, S, CTX, ATM & + & $\mathrm{B}(2), \mathrm{C} 2(2)$ & $\begin{array}{l}\text { S. Kentucky (1), } \\
\text { N/A (2) }\end{array}$ & 3 & 1 \\
\hline
\end{tabular}

$\$$ N/A: not applicable.

$\dagger$, Antibiotics listed in the antibiotic profile are those that demonstrated $100 \%$ resistance with all tested isolates.

AM, Ampicillin; ATM, Azetronam; C, Chloramphenicol; CAZ, Ceftazidime; CIP, Ciprofloxacin; CTX, Cefotaxime; GM, Gentamicin; NA, Nalidixic acid; S, Streptomycin; SAM, Ampicillin/sulbactam; SUL, Sulfonamide compounds; SXT, Sulfamethoxazole/Trimethoprim; TE, Tetracycline; TIM, Ticarcillin clavulanate.

Interestingly, studies in France, ${ }^{30}$ Switzerland ${ }^{31}$ and the Slovak Republic ${ }^{32}$ have reported that infection with $S$. Kentucky strains resistant to ciprofloxacin was associated with travel to Egypt, Morocco and other countries in the North African region. Corroborating these studies, our results indicate that the most prevalent serotype in Cairo, Egypt is S. Kentucky, with high rates of resistance to ciprofloxacin. S. Enteritidis was isolated at a very low rate, and $S$. Typhimurium was not detected at all. This is comparable to the results from Senegal, 27,29 where $S$. Kentucky was also found to be the most prevalent serotype ( $30 \%$ of the total isolates). The observed low isolation rates for $S$. Enteritidis and $S$. Typhimurium in this study may result from replacement by other serotypes (54\% were not serotyped in this study).

The remarkably high rates of antibiotic resistance exhibited by Salmonella strains from this study, particularly against sulfamethoxazole $(97.4 \%)$, nalidixic acid $(96.2 \%)$, tetracycline (96.2\%), ampicillin (75.6\%) and streptomycin (35.9\%), are probably because of the early introduction and consequent widespread use of these antibiotics in veterinary and human medicine in Egypt. The high resistance rates to nalidixic acid and ciprofloxacin are of particular note, since quinolones have been considered one of the last options for the treatment of MDR Salmonella.

All S. Kentucky strains tested in this study were MDR and demonstrated significantly higher rates of resistance than other Salmonella serotypes to ciprofloxacin (97\% vs. $2.5 \%$; $p<0.01)$ and ticarcillin/clavulanate ( $94 \%$ vs. $42.5 \% ; p<0.01)$. The correlation between antibiogram and serotype suggests poor infection control practices in the poultry production industry, which may facilitate the spread of these MDR $S$. Kentucky strains.

The most common mode of bacterial-acquired resistance to $\beta$-lactam antibiotics is the $\beta$-lactamase enzyme. ${ }^{34}$ In this study, 30 of 48 poultry meat isolates and 4 of 11 faeces isolates that were ampicillin resistant possessed the blaTEM gene. This result is in agreement with other findings.,17 Recently, ESBL acquisition rates by Salmonella, in particular, have arisen worldwide. In an earlier study conducted on Salmonella isolates from poultry in Egypt, 5\% of the isolates belonging to serovar Poona produced ESBLs. ${ }^{12}$ In this study $8 \%(n=6)$ of Salmonella isolates demonstrated ESBL production, two of them belonging to serovar Kentucky. The detection of an ESBL phenotype in poultry meat and faecal samples in this study may indicate a lack of infectious disease barriers amongst clinics, humans and animals. In addition, approximately half of all antibiotics produced worldwide (many of which are used routinely in humans) are used in animals to prevent infection and consequently improve production. ${ }^{35}$ Unfortunately, this leads to the development of resistant bacteria in animals that can infect humans directly or transfer antibiotic resistance genes to other human pathogens. ${ }^{36}$

Sulphonamides are amongst the most commonly-used antibiotics for food animal production worldwide. ${ }^{37}$ These compounds are bacteriostatic antimicrobial drugs that act by means of competitive inhibition of the enzymes involved in the synthesis of tetrahydrofolic acid. Sulphonamides compete with the structural analogue $p$-aminobenzoic acid binding to dihydropteroate synthetase (DHPS), a catalytic enzyme in the folic acid biosynthesis pathway, thus inhibiting the formation of dihydrofolic acid. ${ }^{38}$ Sulphonamide resistance in Salmonella isolates has been attributed to the presence of an extra sul gene, which expresses an insensitive form of DHPS. In this study, the presence of the sul1 gene was detected in 74 of 76 sulphonamide-resistant isolates. The PCR results were consistent with the antimicrobial susceptibility phenotypes; the sul1 and/or sul2 genes were detected in $97.4 \%$ of the sulphonamide-resistant Salmonella isolates. Other studies have found this gene to be present at moderate to high rates in retail meats and other foods. ${ }^{1,17,39}$

Integrons are genetic elements that are able to recognise and capture mobile gene cassettes carrying the antibiotic 
resistance genes, which leads to MDR distribution and the subsequent limitation of treatment options for infectious diseases.$^{40}$ In this study, PCR screening results of 78 Salmonella isolates detected class 1 integrons in 62 (79.5\%) isolates. Very few studies have investigated class 1 integrons in Salmonella isolates from human, poultry and faeces isolates in Egypt. The presence of integrons was examined in 21 Salmonella isolates from diseased broiler chickens in Egypt where the researchers identified class 1 and class 2 integrons in $42.9 \%$ and $14.3 \%$ of the isolates, respectively. ${ }^{41}$ Lower detection rates were obtained in a study of food isolates in Germany $(65 \%) .{ }^{1}$ A study by Antunes, Machad and Peixe ${ }^{42}$ showed, in a large survey of 1183 Salmonella isolates from various animal, human and food sources, that $75 \%$ carried class 1 integrons. Class 1 integrons have been detected in S. Kentucky. ${ }^{43}$ In our study, 5 isolates of $S$. Kentucky carried the 1950 bp class 1 integron.

Multidrug resistance was observed amongst $82 \%(64 / 78)$ of the isolates, with 59 isolates $(76 \%)$ being resistant to more than 5 antibiotics. Our study indicates that $88.1 \%$ of the 59 MDR isolates harboured class 1 integrons, whilst none of the MDR isolates carried class 2 integrons. Several groups have reported that integron-containing isolates are more antibiotic resistant than those isolates obtained from comparable patients which were lacking an integron. ${ }^{44}$

\section{Limitations}

Samples included in this study were collected from the Cairo Governorate during the six-month period from December 2011 to May 2012. Thus, the results of this study may not be generalisable to other regions or seasons. More studies are needed on samples collected from the Nile Delta and Upper Egypt governorates and during different seasons.

\section{Conclusion}

In conclusion, this study demonstrated a relatively high prevalence of Salmonella-contaminated poultry products, with $S$. Kentucky the most prevalent serotype, in poultry markets in Cairo, Egypt. In addition, this study revealed significant MDR rates, particularly carried by $S$. Kentucky serovar strains, against the $\beta$-lactam and fluoroquinolone (e.g., ciprofloxacin) classes of antibiotics. Ultimately, these trends may limit treatment options and contribute to treatment failure and increased death rates.

More comprehensive studies are needed to better determine the prevalence and antibiotic resistance patterns of Salmonellacontaminated poultry meat and its products. More serotypes should be utilised in identification and be included in a national surveillance database to allow comparisons with findings within Egypt and from other countries in the region. This surveillance should include antimicrobial susceptibility profiles to track the emergence and exacerbation of existing drug resistance amongst Salmonella and other food-borne disease pathogens.

\section{Acknowledgements Competing interests}

The authors declare that they have no financial or personal relationship(s) that may have inappropriately influenced them in writing this article.

\section{Disclaimer}

The views expressed in this article are those of the authors and do not necessarily reflect the official policy or position of the US Department of the Navy, the US Department of Defense, the US Government or the Egyptian Ministry of Health and Population.

\section{Copyright assignment statement}

The authors are employees of the US Government. This work was prepared as part of their official duties. Title 17 U.S.C. $\S 105$ provides that 'Copyright protection under this title is not available for any work of the United States Government.' Title 17 U.S.C. $\$ 101$ defines a US Government work as a work prepared by a military service member or employee of the US Government as part of that person's official duties.

\section{Authors' contributions}

M.A-M. (Global Disease Detection and Response Program, US Naval Medical Research Unit) developed the concept, processed the samples and participated in writing the manuscript. B.L.H. (Global Disease Detection and Response Program, US Naval Medical Research Unit), R.F.G. (Ain Shams University) and H.M.A. (Ain Shams University) developed the concept, analysed the results, wrote and reviewed the manuscript. R.A-K. and A.E.-G. (both Bacterial and Parasitic Disease Research Program, US Naval Medical Research Unit) participated and supervised the molecular biology work and helped in analysing the results and writing the manuscript.

\section{References}

1. Miko A, Pries K, Schroeter A, et al. Molecular mechanisms of resistance in multidrug-resistant serovars of Salmonella enterica isolated from foods in Germany. J Antimicrob Chemother. 2005;56(6):1025-1033. http://dx.doi. org/10.1093/jac/dki365

2. Kümmerer K. Resistance in the environment. J Antimicrob Chemother 2004;54(2):311-320. http://dx.doi.org/10.1093/jac/dkh325

3. Helms M, Simonsen J, Mølbak K. Quinolone resistance is associated with increased risk of invasive illness or death during infection with Salmonella serotype Typhimurium. J Infect Dis. 2004;190(9):1652-1654. http://dx.doi. org/10.1086/424570

4. Aarestrup FM, Hasman $\mathrm{H}$, Olsen I, et al. International spread of blaCMY-2mediated cephalosporin resistance in a multiresistant Salmonella enterica serovar Heidelberg isolate stemming from the importation of a boar by Denmark from Canada. Antimicrob Agents Chemother. 2004;48(5):1916-1917. http://dx.doi. org/10.1128/AAC.48.5.1916-1917.2004

5. Paterson DL, Bonomo RA. Extended-spectrum $\beta$-lactamases: a clinical update. Clin Microbiol Rev. 2005;18(4):657-686. http://dx.doi.org/10.1128/CMR.18.4. 657-686.2005

6. Siu LK, Lo JYC, Yuen KY, et al. $\beta$-lactamases in Shigella flexneri isolates from Hong Kong and Shanghai and a novel OXA-1-like $\beta$-lactamase, OXA-30. Antimicrob Agents Chemother. 2000;44(8):2034-2038. http://dx.doi.org/10.1128/AAC.44.8 2034-2038.2000

7. Bouchillon SK, Johnson BM, Hoban DJ, et al. Determining incidence of extended spectrum beta-lacamase producing Enterobacteriaceae, vancomycin-resistant
Enterococcus faecium and methicillin-resistant Staphylococcus aureus in 38 centres from 17 countries: The PEARLS study 2001-2002. Int J Antimicrob Agents. 2004;24(2):119-124. http://dx.doi.org/10.1016/j.ijantimicag.2004.01.010 
8. Fluit AC. Towards more virulent and antibiotic-resistant Salmonella? FEMS Immunol Med Microbiol. 2005:43(1):1-11. http://dx.doi.org/10.1016/j.femsim. 2004.10.007

9. Recchia GD, Hall RM. Gene cassettes: A new class of mobile element. Microbiology. 1995;141(Pt 12):3015-3027. http://dx.doi.org/10.1099/ 13500872-141-12-3015

10. Rodriguez I, Rodicio MR, Herrera-León S, et al. Class 1 integrons in multidrug resistant non-typhoidal Salmonella enterica isolated in Spain between 2002 and 2004. Int J Antimicrob Agents. 2008;32(2):158-164. http://dx.doi.org/10.1016/j. ijantimicag.2008.03.005

11. Wasfy MO, Frenck R, Ismail TF, et al. Trends of multiple-drug resistance among Salmonella serotype Typhi isolates during a 14-year period in Egypt. Clin Infect Dis. 2002;35(10):1265-1268. http://dx.doi.org/10.1086/343052

12. Aouf A, Messai $Y$, Salama MS, et al. Resistance to $\beta$-lactams of human and veterinary Salmonella isolates in Egypt and Algeria. Afr J Microbiol Res. 2011;5(7):802-808.

13. International Organization for Standardization (ISO). ISO 6579:2002 Microbiology of food and animal feeding stuffs - horizontal method for the detection of Salmonella spp. Geneva, Switzerland: ISO; 2002.

14. Popoff MY. Antigenic formulas of the Salmonella serovars, 8th ed. Paris, France: WHO Collaborating Center for Reference and Research on Salmonella, Institute Pasteur; 2001.

15. Clinical and Laboratory Standards Institute. Performance standards for antimicrobial susceptibility testing: twentieth informational supplement (M 100-S20). Wayne, PA: CLSI; 2010.

16. Sambrook J, Fritsch EF, Maniatis T. Molecular cloning: A laboratory manual. 2nd ed. Cold Spring Harbor, NY: Cold Spring Harbor Laboratory Press; 1989.

17. Chen S, Zhao S, White DG, et al. Characterization of multiple-antimicrobialresistant Salmonella serovars isolated from retail meats. Appl Environ Microbiol. 2004;70(1):1-7. http://dx.doi.org/10.1128/AEM.70.1.1-7.2004

18. Kerrn MB, Klemmensen T, Frimodt-Møller $N$, et al. Susceptibility of Danish Escherichia coli strains isolated from urinary tract infections and bacteraemia, and distribution of sul genes conferring sulphonamide resistance. J Antimicrob Chemother. 2002;50(4):513-516. http://dx.doi.org/10.1093/jac/dkf164

19. Goldstein C, Lee MD, Sanchez S, et al. Incidence of class 1 and 2 integrases in clinical and commensal bacteria from livestock, companion animals, and exotics. Antimicrob Agents Chemother. 2001;45(3):723-726. http://dx.doi.org/10.1128/ AAC.45.3.723-726.2001

20. Lévesque $C$, Piché L, Larose $C$, et al. PCR mapping of integrons reveals several novel combinations of resistance genes. Antimicrob Agents Chemother. 1995 39(1):185-191. http://dx.doi.org/10.1128/AAC.39.1.185

21. Hassanein R, Hassan Ali SF, Abd El-Malek AM, et al. Detection and identification of Salmonella species in minced beef and chicken meats by using multiplex PCR in Assiut city. Vet World. 2011;4(1):5-11. http://dx.doi.org/10.5455/ vetworld.2011.5-11

22. Cardinale E, Perrier Gros-Claude JD, Tall F, et al. Prevalence of Salmonella and Campylobacter in retail chicken carcasses in Senegal. Revue Élev Méd Vét Pays Campylobacter in retail chick
Trop. 2003;56(1-2):13-16.

23. Tibaijuka B, Molla B, Hildebrandt G, et al. Antimicrobial susceptibilities of Salmonella isolated from retail raw chicken meat and giblets in Ethiopia. Bull Anim HIth Prod Afr. 2002;50(2):86-95.

24. Del Cerro, A, Soto SM, Landeras E, et al. PCR-based procedures in detection and DNA-fingerprinting of Salmonella from samples of animal origin. Food Microbiology. 2002;19(6):567-575. http://dx.doi.org/10.1006/ fmic.2002.0512

25. Roy P, Dhillon, AS, Lauerman LH, et al. Results of Salmonella isolation from poultry products, poultry, poultry environment, and other characteristics. Avian Dis. 2.0.CO;2
26. Al-Nakhli HM, Al-Ogaily ZH, Nassar TJ. Representative Salmonella serovars isolated from poultry and poultry environments in Saudi Arabia. Rev Sci Tech. 1999;18(3):700-709.

27. Hendriksen RS, Vieira AR, Karlsmose S, et al. Global monitoring of Salmonella serovar distribution from the World Health Organization Global Foodborne Infections Network Country Data Bank: Results of quality assured laboratories from 2001 to 2007. Foodborne Pathog Dis. 2011;8(8):887-900. http://dx.doi. org/10.1089/fpd.2010.0787

28. Goncagül G, Günaydın E, Carlı KT. Prevalence of Salmonella serogroups in chicken meat. Turk J Vet Anim Sci. 2005;29:103-106.

29. Bada-Alambedji R, Fofana A, Seydi $M$, et al. Antimicrobial resistance of Salmonella isolated from poultry carcasses in Dakar (Senegal). Braz J Microbiol. 2006;37(4):510-515. http://dx.doi.org/10.1590/\$1517-83822006000400020

30. Elmadiena MM, El Hussein AA, Muckle CA, et al. Antimicrobial susceptibility and multi-drug resistance of Salmonella enterica subspecies enterica serovars in Sudan. Trop Anim Health Prod. 2013;45(5):1113-1118. http://dx.doi.org/10.1007/ s11250-012-0334-7

31. Le Hello S, Hendriksen RS, Doublet B, et al. International spread of an epidemic population of Salmonella enterica serotype Kentucky ST198 resistant to ciprofloxacin. $\mathrm{J}$ Infect Dis. 2011;204(5):675-684. http://dx.doi.org/10.1093/infdis/jir409

32. Bonalli $M$, Stephan $R$, Käppeli $U$, et al. Salmonella enterica serotype Kentucky associated with human infections in Switzerland: Genotype and resistance trends 2004-2009. Food Res Int. 2011;45(2):953-957. http://dx.doi.org/10.1016/j. foodres.2011.04.051

33. Majtán V, Matján T, Matján J, et al. Salmonella enterica serovar Kentucky: Antimicrobial resistance and molecular analysis of clinical isolates from the Slovak Republic. Jpn J Infect Dis. 2006;59(6):358-362.

34. Livermore DM, Canton R, Gniadkowski M, et al. CTX-M: Changing the face of ESBLs in Europe. J Antimicrob Chemother. 2007;59(2):165-174. http://dx.doi. org/10.1093/jac/dkl483

35. Greenwood D, Finch R, Davey P, et al. Antimicrobial chemotherapy. New York: Oxford University Press; 2007.

36. Stürenburg E, Mack D. Extended spectrum $\beta$-lactamases: Implications for the clinical microbiology laboratory, therapy, and infection control. J Infect Dis. 2003;47(4):273-295.

37. Pezzella C, Ricci A, DiGiannatale, E. et al. Tetracycline andstreptomycin resistance genes, transposons, and plasmids in Salmonella enterica isolates from animals in Italy. Antimicrob Agents Chemother. 2004;48(3):903-908. http://dx.doi. org/10.1128/AAC.48.3.903-908.2004

38. Sköld O. Sulfonamide resistance: Mechanisms and trends. Drug Resist Updat. 2000;3(3):155-160. http://dx.doi.org/10.1054/drup.2000.0146

39. Peirano G, Agers $\varnothing$ Y, Aarestrup FM, et al. Occurrence of integrons and antimicrobial resistance genes among Salmonella enterica from Brazil. J Antimicrob Chemother. 2006;58(2):305-309. http://dx.doi.org/10.1093/jac/dk|248

40. Stokes HW, Hall RM. A novel family of potentially mobile DNA elements encoding site-specific gene-integration functions: Integrons. Mol Microbiol. 1989;3(12):1669-1683. http://dx.doi.org/10.1111/j.1365-2958.1989.tb00153.x

41. Ahmed AM, Shimamoto T. Genetic analysis of multiple antimicrobial resistance in Salmonella isolated from diseased broilers in Egypt. Microbiol Immunol. 2012;56(4):254-261. http://dx.doi.org/10.1111/j.1348-0421.2012.00429.x

42. Antunes $P$, Machado J, and Peixe L. Characterization of antimicrobial resistance and class 1 and 2 integrons in Salmonella enterica isolates from different sources in Portugal. J Antimicrob Chemother. 2006;58:297-304. http://dx.doi. org/10.1093/jac/dkI242

43. Levings RS, Partridge SR, Lightfoot $D$, et al. New integron-associated gene cassette encoding a 3-N-aminoglycoside acetyltransferase. Antimicrob Agents Chemothe 2005;49(3):1238-1241. http://dx.doi.org/10.1128/AAC.49.3.1238-1241.2005

44. Fluit AC, Schmitz FJ. Resistance integrons and super integrons. Clin Microbiol Infect. 2004;10(4):272-288. http://dx.doi.org/10.1111/j.1198-743X.2004.00858.x 